\title{
Autism in Australia: Community Knowledge and Autistic People's Experiences
}

\author{
Sandra C. Jones ${ }^{1}$ (D) $\cdot$ Muhammad Akram $^{2} \cdot$ Chloe S. Gordon $^{1} \cdot$ Nicole Murphy $^{1} \cdot$ Fiona Sharkie $^{3}$ \\ Accepted: 25 November 2020 / Published online: 3 January 2021 \\ (c) The Author(s), under exclusive licence to Springer Science+Business Media, LLC part of Springer Nature 2021
}

\begin{abstract}
This paper presents two studies that explored community attitudes to autism in Australia; and autistic people and their families' perspectives of community attitudes. In Study One 2424 (primarily non-autistic) people completed a survey on autism-related knowledge and attitudes; identifying a number of misperceptions and knowledge gaps in the general community. In Study Two 1353 people (primarily parents and carers of autistic people) completed a survey on autism-related experiences; identifying that the community's awareness of autism does not appear to extend to understanding how to support autistic people. There is a need for more research which integrates the perspectives of both autistic people and the broader community; and the development of communication and education interventions, with rather than about autistic people.
\end{abstract}

Keywords Autism $\cdot$ Community perceptions $\cdot$ Attitudes $\cdot$ Understanding $\cdot$ Knowledge

Autism Spectrum Condition (ASC) is a neurodevelopmental condition that causes anatomical and functional differences in the brain, resulting in difficulties in social communication, repetitive behaviours, and restricted interests (Hadjikhani 2014). The definition of autism historically focused on deficits. Neurodiversity is an emerging term that moves away from a focus on deficit to a focus on neurological differences (Zolyomi and Tennis 2017). This model views disability as being caused by the failures of the environment to accommodate the autistic person's needs (den Houting 2018), and recognises that autism is also associated with strengths, particularly in the areas of attention to, and memory for, detail and a strong drive to detect patterns (Baron-Cohen 2017).

Supplementary Information The online version contains supplementary material available at https://doi.org/10.1007/s1080 3-020-04819-3.

Sandra C. Jones

sandra.jones@acu.edu.au

1 ACU Engagement, Australian Catholic University, Level 2, 340 Albert St, St Patrick's CampusEast Melbourne, VIC 3002, Australia

2 Mary Mackillop Institute for Health Research, Australian Catholic University, Level 5, 215 Spring St, Melbourne, VIC 3000, Australia

3 Amaze, Registered Charity, 24 Drummond St, Carlton, VIC 3053, Australia
Studies reporting on the prevalence (i.e. number of diagnosed individuals in the total population) and incidence (i.e. number of new diagnoses per year) of autism have shown a steady climb over the past two decades (Russell et al. 2015; May, Sciberras, Brignell, and Williams 2017). The 2015 Australian Survey of Disability, Ageing and Carers (SDAC) reported a $42 \%$ increase in prevalence of autism from 2012 (ABS 2015). According to the 2017 Autism in Australia report, autism is most prevalent among children aged five to 14 (AIHW 2017). These statistics can incorrectly give the impression that children 'grow out' of autism (Jones 2019). In reality, autism is a lifelong condition with autistic adults also needing appropriate supports and services to help them thrive as autistic adults (Cummins, Pellicano, and Crane 2020).

This rise in the prevalence and incidence of autism has resulted in concern over the perception of an 'autism epidemic'. This myth, fueled by media reports, has both increased public awareness of autism and sparked concerns about the 'expanding' incidence of autism (Bennett et al. 2018). Although the reported incidence and prevalence of autism has increased, there are a number of explanations for this rise; including higher rates of seeking diagnoses due to increases in public awareness of autism, and increasing diagnoses of autistic people with lower support needs due to changes in diagnostic criteria and expectations for social communication and behaviour (May et al. 2017). 
Unfortunately, the 'autism epidemic' has an impact not only on public anxiety about autism but, by extension, negative impacts on autistic people (Bennett et al. 2018), who can be misperceived as needing to be pitied and cured (Dosch 2019). Neurodiversity theory provides a helpful platform for beginning to shift the deficit and fear-based discourse associated with the perception of an 'autism epidemic', to one that embraces different types of thinking (Bennett et al. 2018).

Approaches to the diagnosis of autism have historically lacked consistency (Geoghegan, O'Callaghan, and Offit 2020a, b). A qualitative study conducted with 14 autistic women found that their late diagnosis was often because doctors and educators mistakenly believed that autism is a male condition, therefore missing the signs of autism in females (Bargiela, Steward, and Mandy 2016). The Australian government has recently announced a new national standard for the diagnosis of autism in Australia that aims to address the lack of consistency in diagnosis of autism. The guidelines adopt a person-centered approach, which emphasise listening to individuals and their families about their strengths and needs (Geoghegan, O'Callaghan, and Offit 2020a, b). Early, timely, and accurate identification and diagnosis is critical to ensure that autistic people receive appropriate support services. For many families, the lack of accessibility of diagnostic services remains a substantial barrier to care (Bent, Barbaro, and Dissanayake 2020).

Research on community perceptions of autism has found that most people have heard of autism, however they have low levels of understanding of the prevalence of autism and needs of autistic people. For example, a study conducted with a general population of 1204 adults in Northern Ireland found that knowledge of the strengths and challenges faced by autistic individuals was relatively accurate, but perceptions of interventions and service provider responsibilities were vague and uncertain. For those who reported knowing an autistic person, it was more commonly a child (69\%) than an adult (23\%) or both adults and children (7\%). The prevalence of autism was underestimated by most participants (Dillenburger et al. 2013).

A nationally representative survey conducted in France found that $100 \%$ of respondents recognised the term autism, however only $67 \%$ were able to describe some of the characteristics of this diagnosis (Durand-Zaleski et al. 2012). A study with a random sample of 440 adults in Denmark (Jensen et al. 2016) found that the characteristic behaviours of autistic people were recognised by $54.4-76.5 \%$ of the respondents.

Autism is a condition which is surrounded by misperceptions and myths; even when scientifically disproven, these myths can be difficult to dispel. Perhaps the most well-known is the myth that autism is caused by vaccination; while this has been strongly and repeatedly discredited (Geoghegan, O'Callaghan, and Offit 2020a, b), the anti-vaccine movement still prevails in some settings (Davidson 2017). The stereotype of autism conveys that autistic people have no empathy (Hadjikhani 2014), are disinterested in social relationships (John et al. 2018), and are troubled or emotionally unstable (Solomon 2020). An increasing body of research discredits this perception; while autistic people may have difficulty understanding social situations, they have similar or even greater levels of empathy than neurotypical people (Fletcher-Watson and Bird 2019; Hadjikhani 2014), are often interested in forming relationships (John et al. 2018), and experience a strong association between lack of friendship and loneliness which impacts emotional functioning (Mazurek 2014). The belief that autism destroys families, and that typical siblings are denied a normal childhood and burdened for life by autistic siblings, denies the "actual rich, positive complexities that many autistic families experience" (Dosch 2019, p.156). Importantly, it downplays the reality that many of the barriers faced by autistic families are due to factors such as a lack of a social support system and financial stress (Dosch 2019). A number of these myths are perpetuated by the media, with stories presenting autistic people as engaging in criminal behaviour, when the rate of such behaviour in autistic people is actually lower than in the general population (Solomon 2020). A study with 60 participants in the US found that the media and word of mouth were the most frequent sources of information about autism (Jacoby, Walton, and Guada 2019).

Harrison et al. (2017) conducted an international review of autism knowledge assessment measures. The review found that $52 \%$ of the studies were conducted in Northern America, and most focused on knowledge alone rather than assessing both knowledge and attitudes. To date, research on community attitudes has largely been undertaken in Europe, using relatively small samples (between 440 and 1200 in the studies cited above), and has focused solely on the perceptions of the neurotypical population.

This paper reports on two studies that were undertaken to provide an understanding of community attitudes to autism and the experiences of autistic people in Australia. Study One included respondents from all seven Australian states and territories; whereas Study Two focused on autistic people and their families residing in the state of Victoria. The Australian context differs from other contexts, such as the US, due to differences in population size, health care systems, funding mechanisms, and organisation of allied health services (Garg et al. 2016).

This study therefore explores the adequacy of support received by autistic people; and compares and contrasts the perspectives of the general Australian population to the lived experience of autistic people and their families and carers in Australia. Study One used an online panel to explore community knowledge and attitudes; and Study Two used a direct mail online survey to explore experiences. 


\section{Study One}

\section{Method}

\section{Participants}

The sample consisted of Australian adults aged 18 years and older recruited through a mixed-mode approach, consisting of online and telephone surveys; conducted via the Life in Australia panel (a probability-based online survey panel that is generalisable to the Australian adult population). Members of the panel $(n=3204)$ were invited to take part in the survey via email, SMS, and telephone, with reminders over a two to three week period. Of these, $75.7 \%(n=2424)$ participated in the survey; the majority $(86.9 \%)$ completed the survey online $(78.3 \%$ accessing the online survey via an email link and $8.6 \%$ accessing the online survey via an SMS link); with the remaining $13.1 \%$ completing a telephone interview.

\section{Questionnaire Development}

The questions were developed specifically for this study but were informed by previous studies of community attitudes reported in the academic literature; and the research that underpinned the UK National Autistic Society's "Too Much Information" campaign. Although there are existing measures of autism knowledge and attitudes (Harrison et al. 2017), these have been developed predominantly by neurotypical researchers in the absence of input from autistic individuals during survey development (e.g. McClain et al. 2020) and/or focus on a narrowly defined or specific population (e.g. Segall 2008). To ensure that we addressed areas of importance to the autistic community, the questions were developed by, and in consultation with, autistic people and parents and carers of autistic people.

A primary aim of the survey was to measure understanding of autism and levels of belief in facts and myths. The question indicated that autism is also known as Autism Spectrum Disorder and includes Asperger's Syndrome. The five key areas of knowledge addressed were:

- Awareness: three items addressing whether they have heard of autism, and whether and to what extent they have contact with autistic person(s)

- Prevalence: three items addressing knowledge that prevalence is increasing, that autism effects males and females, and that female diagnoses are increasing

- Causation: five items addressing knowledge/perceptions of the causes of autism

- Outcomes: two items addressing beliefs that autism can be cured and that people grow out of autism
- Impact: nine items addressing knowledge/perceptions of the impact of autism on the individual, such as sensory issues, need for processing time, and anxiety resulting from unexpected changes.

The development and finalisation of the survey questions was undertaken in collaboration with health and communication professionals and members of the autistic community, with the lead researcher an autistic autism researcher. The draft survey was reviewed at three timepoints by a panel of those with lived experience of autism, with adjustments made to the questions and response options to ensure the inclusion of the issues and concerns important to the community. For each area of knowledge we included key facts and known myths; for example, 'autism can be inherited or genetic' (fact) and 'autism is caused by vaccines like MMR' (myth). The prevalence and effects questions included three response options: 1 (true), 2 (false), and 3 (not sure); and the awareness and causation questions used a five-point scale ranging from 1 (strongly agree) to 5 (strongly disagree), with an additonal 'not sure' option.

The questionnaire commenced with top-of-mind social issues ("What do you think are the three major social problems or issues in Australia today?"). ${ }^{1}$ Respondents were then presented with a written scenario about a child's behaviour in a store and asked a series of questions about their perceptions, emotions, and reactions if they were in this hypothetical scenario. ${ }^{1}$ Respondent demographics were also collected; including age, gender, educational attainment, and workforce participation.

\section{Analysis}

As this was a study of knowledge and attitudes of the general community, participants who had not heard of, or not sure if they had heard of, autism were excluded from analyses. Further, the responses for those who did not identify as autistic or as having a close relative as autistic (hereafter referred to as non-autistic) were analysed separately $(\mathrm{n}=2081)$; and the results section commences with these findings. These responses are then compared to those from respondents who self-identified as autistic $(n=23)$ and those who report having a close relative who is autistic but not themselves being autistic $(n=328)$.

The demographic characteristics of the respondents are reported in Table 1. The respondent sample is consistent with the Australian population by gender; Socio-Economic Indexes of Areas (SEIFA) quintile; state of residence; capital city versus other; and Australian versus overseas-born. The sample was more highly educated than the underlying

$\overline{1}$ Data not reported; included in supplementary material. 
Table 1 Descriptive demographic characteristics for study one participants

\begin{tabular}{|c|c|c|c|c|}
\hline \multirow[t]{2}{*}{ Characteristic } & \multirow{2}{*}{$\begin{array}{l}\begin{array}{l}\text { Non-autistic } \\
(\mathrm{n}=2032)\end{array} \\
n(\%)\end{array}$} & \multirow[b]{2}{*}{ Australia ${ }^{1} \%$} & \multirow{2}{*}{$\begin{array}{l}\text { Autistic }(\mathrm{n}=23) \\
\mathrm{n}(\%)\end{array}$} & \multirow{2}{*}{$\begin{array}{l}\begin{array}{l}\text { Close relative } \\
(\mathrm{n}=328) \\
\mathrm{n}(\%)\end{array}\end{array}$} \\
\hline & & & & \\
\hline \multicolumn{5}{|l|}{ Gender } \\
\hline Male & $958(47.1)$ & 49.8 & $18(78.3)$ & $120(36.6)$ \\
\hline Female & $1068(52.6)$ & 50.2 & $4(17.4)$ & $207(63.1)$ \\
\hline Other & $2(0.10)$ & & $1(4.3)$ & $1(0.3)$ \\
\hline Missing & $4(0.20)$ & & & \\
\hline \multicolumn{5}{|l|}{ Age } \\
\hline $18-24$ & $140(6.9)$ & 12.3 & $7(30.4)$ & $19(5.8)$ \\
\hline $25-34$ & $261(12.8)$ & 19.1 & $5(21.7)$ & $32(9.8)$ \\
\hline $35-44$ & $269(13.2)$ & 17.5 & $3(13.0)$ & 49 (14.9) \\
\hline $45-54$ & $354(17.4)$ & 16.9 & $3(13.0)$ & $47(14.3)$ \\
\hline $55-64$ & $448(22.0)$ & 14.8 & $3(13.0)$ & $79(24.1)$ \\
\hline $65-74$ & $389(19.1)$ & 10.9 & $2(8.7)$ & $67(20.4)$ \\
\hline $75+$ & $164(8.1)$ & 8.4 & 0 & $35(10.7)$ \\
\hline Missing & $7(0.3)$ & & 0 & 0 \\
\hline \multicolumn{5}{|l|}{ Highest educational qualification } \\
\hline Bachelor or higher & $825(40.6)$ & 23 & $11(47.8)$ & $116(35.4)$ \\
\hline Trade/certificate/diploma & $684(33.7)$ & 31.1 & $9(39.1)$ & $128(39.0)$ \\
\hline Year 12 or equivalent & $226(11.1)$ & 18.3 & $3(13.0)$ & $38(11.6)$ \\
\hline Year 11 or less & $297(14.6)$ & 25.1 & 0 & $46(14.0)$ \\
\hline \multicolumn{5}{|l|}{ Household structure } \\
\hline Person living alone & $357(17.6)$ & & $8(34.8)$ & $59(18.0)$ \\
\hline Couple only & $678(33.4)$ & & $4(17.4)$ & $98(29.9)$ \\
\hline Couple with kids & $642(31.6)$ & & $8(34.8)$ & $117(35.7)$ \\
\hline Single parent with kids & $117(5.8)$ & & $2(8.7)$ & $25(7.6)$ \\
\hline Others & $223(11.0)$ & & $1(4.3)$ & $27(8.2)$ \\
\hline Missing & $15(0.7)$ & & 0 & $2(0.6)$ \\
\hline \multicolumn{5}{|l|}{ Country of birth } \\
\hline Australia & $1454(70.8)$ & 71.6 & $20(87.0)$ & $263(80.2)$ \\
\hline Other & $566(28.5)$ & 27.8 & $3(13.0)$ & $63(19.2)$ \\
\hline Missing & $12(0.6)$ & & 0 & $2(0.6)$ \\
\hline \multicolumn{5}{|l|}{ Socio-Economic Indexes for Areas } \\
\hline Quartile 1- Most disadvantage & $254(12.5)$ & 16 & $6(26.1)$ & $37(11.3)$ \\
\hline Quartile 2 & $347(17.1)$ & 18 & $5(21.7)$ & $65(19.8)$ \\
\hline Quartile 3 & $385(18.9)$ & 20 & $3(13.0)$ & $76(23.2)$ \\
\hline Quartile 4 & $449(22.1)$ & 22 & $4(17.4)$ & $66(20.1)$ \\
\hline Quartile 5 - Least disadvantage & $575(28.3)$ & 24 & $5(21.7)$ & $84(25.6)$ \\
\hline Missing & $22(1.1)$ & & 0 & 0 \\
\hline \multicolumn{5}{|l|}{ Region } \\
\hline Capital city & $1393(66.9)$ & 67 & $14(60.9)$ & $209(63.7)$ \\
\hline Rest of the state & $666(32.0)$ & 33 & $9(39.1)$ & $119(36.3)$ \\
\hline Missing & $22(1.1)$ & & & \\
\hline \multicolumn{5}{|l|}{ State } \\
\hline NSW & $586(28.8)$ & 32.0 & $11(47.8)$ & $99(30.2)$ \\
\hline VIC & $492(24.2)$ & 25.2 & $2(8.7)$ & $90(27.4)$ \\
\hline QLD & $411(20.2)$ & 20.1 & $8(34.8)$ & $57(17.4)$ \\
\hline SA & $185(9.1)$ & 7.1 & $1(4.3)$ & $31(9.5)$ \\
\hline WA & $238(11.7)$ & 10.9 & 0 & $33(10.1)$ \\
\hline TAS & $56(2.8)$ & 2.2 & 0 & $7(2.1)$ \\
\hline NT & $15(0.7)$ & 1.0 & 0 & $3(0.9)$ \\
\hline ACT & $49(2.4)$ & 1.6 & $1(4.3)$ & $8(2.4)$ \\
\hline
\end{tabular}

${ }^{1}$ ABS. (2016a). Australian Demographic Statistics, Sep 2016

https://www.abs.gov.au/AUSSTATS/abs@.nsf/DetailsPage/3101.0Sep\%202016?OpenDocument ABS. (2016b). Education and Work, Australia, May 2016

https://www.abs.gov.au/AUSSTATS/abs@.nsf/DetailsPage/6227.0May\%202016?OpenDocument 
population ( $40 \%$ with bachelor or higher degree compared to $23 \%$ of the population); and while the overall age distribution was not significantly different, there was a greater proportion of people aged 55 and over in the sample than in the underlying Australian population (ABS 2016a, b).

Descriptive statistics have been used to summarise survey data. The summary statistics are reported as frequencies and percentages for all categorical variables. To examine the relationship between two variables measured at the nominal or ordinal level of measurement, bivariate tables (or contingency tables) were prepared. To test the association between variables (such as differences by age group or gender), generalised linear model (GLM) was applied to binary response variable, ordinal regression model (ORM) was applied to ordinal response (such as strongly agree to strongly disagree), and chi-square tests were performed for all other categorical data. The results for the GLM and ORM are expressed as odds ratios (OR) with $95 \%$ confidence intervals (95\% CI) along with p-value. All analyses were performed in statistical software R (R Core Team 2019) version 3.5.3.

\section{Results}

A total of 2383 respondents were included in the analysis, after excluding the 48 who had not heard of, or not sure if they had heard of, autism. There were no significant differences by age, gender, education level, or state of residence for the majority of the questions; where such differences were identified they are explicitly stated in the results. ${ }^{1}$ The majority (97.6\%) of the respondents reported that they had heard of autism; $1.1 \%(\mathrm{n}=23)$ had not and $1.2 \%(\mathrm{n}=25)$ were not sure.

Over $83 \%$ of the non-autistic respondents reported that they have contact with at least one autistic person; $15 \%$ $(n=187)$ a lot of contact and 67.8\% $(n=844)$ a little contact. About one in 10 reported having an autistic family member ${ }^{2}$ (11.7\%); $18.7 \%$ a friend; $15.4 \%$ an acquaintance; $4.6 \%$ a coworker or colleague; and $25.5 \%$ someone else.

\section{Prevalence}

More than half of the non-autistic respondents (61.3\%) (correctly) agreed that the number of autistic people is increasing and a further $32.5 \%$ were unsure. They were less confident that the number of autistic girls is increasing (correct) (37.8\% said this was true and 54\% were unsure); although only $1.3 \%$ (incorrectly) believed that autism only affects males, with a further $7.4 \%$ unsure (See Table 2). Females were more likely than males to believe that the number of autistic people is increasing in Australia $(\mathrm{OR}=1.68$, CI: $1.15-2.45 ; \mathrm{p}=0.007$, using GLM).

Autistic people and those with close relatives who are autistic were more likely than the non-autistic population to agree that the number of autistic people is increasing $\left(\chi^{2}=26.03, p<0.001\right)$ and more likely to agree that the number of autistic girls is increasing $\left(\chi^{2}=16.05, p=0.003\right)$.

\section{Causation}

More than one-third of non-autistic respondents (correctly) agreed that scientists do not know the causes of autism (41\%) and that autism can be inherited or genetic (45.8\%); approximately $12 \%$ disagreed with each of these statements, and $30.6 \%$ and $26.1 \%$ respectively were unsure (Table 3 ).

There were a number of knowledge gaps identified. For example, while only $3 \%$ of non-autistic respondents agreed with the (incorrect) statement that autism is caused by vaccines like MMR, $20 \%$ were unsure whether this is true; $27 \%$ agreed or were unsure that autism is caused by something in the environment and $3 \%$ by poor parenting skills (all incorrect). Older respondents were less likely to agree that autism can be inherited or genetic ( $\mathrm{OR}=2.41, \mathrm{CI}: 1.89-3.09$; $\mathrm{p}<0.001$, using ORM) and less likely to strongly disagree that it is caused by poor parenting skills $(\mathrm{OR}=0.51, \mathrm{CI}$ : $0.40-0.65 ; \mathrm{p}<0.001$, using ORM).

Autistic people and those with close relatives who are autistic were more likely to (correctly) agree that scientists do not know the causes of autism $\left(\chi^{2}=30.25, \mathrm{p}<0.001\right)$. Of concern, those with close relatives who are autistic were more likely than non-autistic respondents or autistic people themselves to (incorrectly) believe that autism is caused by vaccines like MMR $\left(\chi^{2}=33.33, \mathrm{p}<0.001\right)$.

\section{Outcomes}

More than one in five (22.2\%) of the non-autistic respondents (incorrectly) believed it was true or were unsure whether people with autism grow out of the condition. Only slightly more than half $(53.7 \%)$ were aware that autism cannot be cured; $10.6 \%(\mathrm{n}=215)$ thought that it can and $35.6 \%(n=724)$ were unsure. Female respondents were more likely than males to be aware that autism cannot be cured $(\mathrm{OR}=2.81$, CI: 2.06-3.85; $\mathrm{p}<0.001$, using GLM $)$ and less likely to believe that people with autism will grow out of the condition ( $\mathrm{OR}=0.52$, CI: $0.33-0.82 ; \mathrm{p}=0.005$, using GLM).

\section{Impact}

The majority of the non-autistic respondents were aware that autism affects everyone differently (88.4\%), that autistic people may be sensitive to light and noise (85.6\%), that they have difficulty making friends (77.9\%), and that they struggle to gain employment (76.8\%). Of concern, $19.2 \%$ 
Table 2 Descriptive and chi-square test results for study one knowledge questions

\begin{tabular}{|c|c|c|c|c|}
\hline Statement & True $\%$ & Unsure \% & False \% & $\mathrm{p}$-value \\
\hline \multicolumn{5}{|c|}{ Autism affects everyone differently } \\
\hline Autistic & 91.3 & 0 & 8.7 & 0.001 \\
\hline Close Relative & 93.6 & 5.2 & 1.2 & \\
\hline Non-autistic & 88.4 & 9.5 & 2.0 & \\
\hline \multicolumn{5}{|c|}{ Sensitive to light and noise } \\
\hline Autistic & 100 & 0 & 0 & 0.004 \\
\hline Close Relative & 92.4 & 6.4 & 1.2 & \\
\hline Non-autistic & 85.6 & 12.0 & 2.4 & \\
\hline \multicolumn{5}{|c|}{ Difficulty making friends } \\
\hline Autistic & 91.3 & 4.3 & 4.3 & 0.084 \\
\hline Close Relative & 80.8 & 7.6 & 11.6 & \\
\hline Non-autistic & 77.9 & 11.8 & 10.2 & \\
\hline \multicolumn{5}{|c|}{ Struggle to gain employment } \\
\hline Autistic & 87 & 8.7 & 4.3 & 0.085 \\
\hline Close Relative & 72 & 13.4 & 14.3 & \\
\hline Non-autistic & 76.8 & 13.7 & 9.3 & \\
\hline \multicolumn{5}{|c|}{ Number of autistic people increasing } \\
\hline Autistic & 87 & 4.3 & 4.3 & $<0.001$ \\
\hline Close Relative & 71.3 & 22 & 6.7 & \\
\hline Non-autistic & 61.3 & 32.5 & 6.1 & \\
\hline \multicolumn{5}{|c|}{ Autism is a mental health condition } \\
\hline Autistic & 52.2 & 13 & 34.8 & 0.307 \\
\hline Close Relative & 56.7 & 11.3 & 31.7 & \\
\hline Non-autistic & 60.7 & 16.9 & 22.1 & \\
\hline \multicolumn{5}{|c|}{ Number of girls with autism is increasing } \\
\hline Autistic & 65.2 & 30.4 & 4.3 & 0.003 \\
\hline Close Relative & 45.4 & 47.6 & 7 & \\
\hline Non-autistic & 37.8 & 53.9 & 8.2 & \\
\hline \multicolumn{5}{|l|}{ Often violent } \\
\hline Autistic & 8.7 & 13 & 78.3 & 0.055 \\
\hline Close Relative & 17.1 & 13.4 & 68.6 & \\
\hline Non-autistic & 19.2 & 21.0 & 59.5 & \\
\hline \multicolumn{5}{|c|}{ School can refuse to enrol } \\
\hline Autistic & 21.7 & 13 & 65.2 & 0.008 \\
\hline Close Relative & 18 & 30.5 & 51.5 & \\
\hline Non-autistic & 17.6 & 34.7 & 47.6 & \\
\hline \multicolumn{5}{|c|}{ Should go to specialist school } \\
\hline Autistic & 8.7 & 4.3 & 87 & 0.096 \\
\hline Close Relative & 9.1 & 7.6 & 82.6 & \\
\hline Non-autistic & 14.5 & 12.9 & 72.4 & \\
\hline \multicolumn{5}{|c|}{ Grow out of condition } \\
\hline Autistic & 4.3 & 13 & 82.6 & 0.486 \\
\hline Close Relative & 6.7 & 10.1 & 83.2 & \\
\hline Non-autistic & 4.1 & 18.1 & 77.7 & \\
\hline \multicolumn{5}{|l|}{ Can’t play sport } \\
\hline Autistic & 0 & 0 & 100 & 0.039 \\
\hline Close Relative & 2.7 & 3.7 & 93.6 & \\
\hline Non-autistic & 2.5 & 7.1 & 90.5 & \\
\hline \multicolumn{5}{|c|}{ Autism only affects males } \\
\hline Autistic & 0 & 0 & 100 & 0.060 \\
\hline Close Relative & 0.3 & 4.9 & 94.8 & \\
\hline G Non-autistic & 1.3 & 7.4 & 91.2 & \\
\hline
\end{tabular}

Table 2 (continued)

Autistic $=$ responding as an autistic person $(n=23)$, Close relative $=$ responding as a close relative of an autistic person $(n=328)$, and Non-autistic $=$ neither autistic or close relative of an autistic person $(\mathrm{n}=2032)$

(incorrectly) believed that people with autism are often violent (and a further $21 \%$ were unsure) and $17.6 \%$ (incorrectly) believed that schools can refuse to enrol a student with autism (and $34.7 \%$ were unsure).

Females were more likely than males to (correctly) believe that autism affects everyone differently $(\mathrm{OR}=2.40$, CI: $1.27-4.76 ; p=0.009)$, that autistic people are sensitive to light or noise $(\mathrm{OR}=2.11, \mathrm{CI}: 1.18-3.86 ; \mathrm{p}=0.012)$, and that they have difficulty making friends $(\mathrm{OR}=1.47, \mathrm{CI}$ : $1.09-1.97 ; p=0.011)$; but are less likely to believe that autistic people should go to a specialist school $(\mathrm{OR}=0.55$, CI: $0.42-0.72 ; \mathrm{p}<0.001)$ or that they can't play sports $(\mathrm{OR}=0.48$, CI: $0.26-0.86 ; \mathrm{p}=0.015)$. Females were also more likely to believe that autistic people are often violent $(\mathrm{OR}=1.43$, CI: $1.13-1.82 ; \mathrm{p}=0.003)$; as were respondents with a lower level of educational attainment $(\mathrm{OR}=2.43$, CI: $1.80-3.27 ; \mathrm{p}<0.001)$. Older respondents were more likely to believe that autistic people are often violent $(\mathrm{OR}=2.32$, CI: $1.72-3.13 ; \mathrm{p}<0.001)$ or should go to a specialist school $(\mathrm{OR}=2.34$, CI: $1.68-3.29 ; \mathrm{p}<0.001)$. All above results based on GLM.

Autistic people and those with close relatives who are autistic were more likely than the non-autistic sample to agree that autism affects everyone differently $\left(\chi^{2}=17.94\right.$, $\mathrm{p}=0.001$ ), that autistic people may be sensitive to light and noise $\left(\chi^{2}=15.28, p=0.004\right)$, and that schools can refuse to enrol a student with autism $\left(\chi^{2}=13.82, p=0.008\right)$.

\section{Study Two}

\section{Method}

\section{Participants}

The sampling frame for Study Two was persons aged 18 years and over who are autistic and/or are a family member/carer of an autistic person, and who subscribe to the Amaze (state-based autism organisation) mailing list. Respondents were recruited to participate in the online survey via email invitation and two subsequent reminder emails. Invitations to complete the online survey were sent to 14,334 subscribers. A small proportion of the sample was found to be unusable due to the email address no longer existing or being incorrect (1.86\%).

Of those subscribers sent an invitation, 1353 completed the survey with an average duration of $14.9 \mathrm{~min}$. A further 
Table 3 Descriptive results for what study one participants think causes autism

\begin{tabular}{|c|c|c|c|c|c|c|c|c|}
\hline Statement & & $\begin{array}{l}\text { Strongly } \\
\text { agree } \%\end{array}$ & Agree $\%$ & $\begin{array}{l}\text { Neither agree } \\
\text { nor disagree } \%\end{array}$ & Disagree \% & $\begin{array}{l}\text { Strongly } \\
\text { disagree } \\
\%\end{array}$ & Unsure \% & P-value \\
\hline \multirow[t]{3}{*}{ Scientists don't know what causes autism } & Autistic & 21.7 & 43.5 & 21.7 & 8.7 & 0 & 4.3 & $<0.001$ \\
\hline & Close relatives & 14.3 & 36.9 & 18 & 7.9 & 2.1 & 20.4 & \\
\hline & Non-autistic & 8.1 & 32.9 & 16.1 & 9.9 & 2.4 & 30.6 & \\
\hline \multirow[t]{3}{*}{ Can be inherited or genetic } & Autistic & 17.4 & 39.1 & 21.7 & 4.3 & 4.3 & 13 & 0.253 \\
\hline & Close relatives & 12.8 & 43.9 & 14 & 8.2 & 3 & 18 & \\
\hline & Non-autistic & 8.8 & 37.0 & 15.6 & 9.7 & 2.8 & 26.1 & \\
\hline \multirow[t]{3}{*}{ Caused by something in the environment } & Autistic & 4.3 & 0 & 26.1 & 17.4 & 43.5 & 8.7 & 0.002 \\
\hline & Close relatives & 0.9 & 6.4 & 20.1 & 28.4 & 26.8 & 17.4 & \\
\hline & Non-autistic & 1.0 & 4.7 & 16.1 & 32.5 & 24.7 & 20.8 & \\
\hline \multirow[t]{3}{*}{ Caused by vaccine like MMR } & Autistic & 0 & 0 & 4.3 & 13 & 78.3 & 4.3 & $<0.001$ \\
\hline & Close relatives & 1.8 & 2.4 & 10.1 & 24.7 & 47.9 & 12.8 & \\
\hline & Non-autistic & 0.9 & 2.0 & 8.8 & 25.3 & 43.3 & 19.5 & \\
\hline \multirow[t]{3}{*}{ Caused by poor parenting skills } & Autistic & 4.3 & 0 & 4.3 & 17.4 & 73.9 & 0 & 0.251 \\
\hline & Close relatives & 0.3 & 0.6 & 2.7 & 22.3 & 73.5 & 0.3 & \\
\hline & Non-autistic & 0.4 & 1.2 & 2.8 & 25.8 & 67.9 & 1.8 & \\
\hline
\end{tabular}

Autistic responding as an autistic person $(\mathrm{n}=23)$, Close relative responding as a close relative of an autistic person $(\mathrm{n}=328)$, and Non-autistic neither autistic or close relative of an autistic person $(n=2032)$

109 respondents attempted to undertake the study but did not meet the selection criteria outlined above. The final participation rate was $9.44 \%$ (of all sample members approached).

The majority of the respondents $(n=1297 ; 96 \%)$ were from the state of Victoria. Due to the very small number of respondents from outside of Victoria $(n=56)$ these were excluded from the analyses. Australia is a federated nation with responsibilities spread between the Commonwealth and State governments. Importantly, education (and many aspects of healthcare) are state responsibilities. Thus, people residing in different states may have differential access and experience of services.

The majority of the sample were female, over 34 years of age, born in Australia, and had a household structure of a couple with children (Table 4). More than half had a bachelor degree or higher. Slightly more than two-thirds $(68.4 \%)$ identified as a family member of an autistic person, $49.4 \%$ as a carer of an autistic person, and 75 (5.8\%) as an autistic person. Those who identified as both an autistic person and a parent/carer of an autistic person were randomly allocated to either the self or other version of the survey; thus, 57 autistic people completed the survey in relation to themselves and the remainder $(\mathrm{n}=18)$ answered in relation to the autistic person they care for. Three-quarters of parents/ carers $(73.7 \%)$ provide care for one person, $18.2 \%$ for two people, and $7.3 \%$ for three or more. For the majority of these respondents $(81.4 \%)$, the oldest person they provide care for is under the age of 18 years (including 19.8\% whose oldest child was under the age of six years and $49.9 \%$ aged 6-12 years).

\section{Questionnaire Development}

The questions were developed specifically for this study but were informed by previous academic literature; and the research that underpinned the UK National Autistic Society's “Too Much Information" campaign. As the aim of this study was to explore the experiences of autistic people on issues of importance to them and in the language that they find respectful, existing measures were not deemed appropriate for this study. Rather, the measures were developed by, and in consultation with, autistic people and parents and carers of autistic people. On completion of the data collection, three autistic researchers who were not involved in the study were invited to review the interpretation of findings presented in the manuscript.

A primary aim of the survey was to promote voices and views of autistic people, as well as what they would most want the public to know about how autism affects them. Again, the draft survey was reviewed at three timepoints by a panel of those with lived experience of autism, with adjustments made to the questions and response options to ensure the inclusion of the issues and concerns important to the community.

The questionnaire included items on:

- Diagnosis: including waiting times for diagnosis

- Support and services: including adequacy of support received

- Perceived community awareness: three items addressing perceptions that people are aware of autism and how to 
Table 4 Descriptive demographic characteristics for study two participants; $\mathrm{N}=1297$ )

\begin{tabular}{|c|c|}
\hline Characteristic & $n(\%)$ \\
\hline \multicolumn{2}{|l|}{ Gender } \\
\hline Male & $130(10.0)$ \\
\hline Female & $1161(89.5)$ \\
\hline Other & $2(0.15)$ \\
\hline Missing & $4(0.3)$ \\
\hline \multicolumn{2}{|l|}{ Age } \\
\hline $18-24$ & $19(1.5)$ \\
\hline $25-34$ & $151(11.6)$ \\
\hline $35-44$ & $603(46.5)$ \\
\hline $45-54$ & $365(28.1)$ \\
\hline $55-64$ & $108(8.3)$ \\
\hline $65-74$ & $38(2.9)$ \\
\hline $75+$ & $6(0.5)$ \\
\hline Missing & $7(0.5)$ \\
\hline \multicolumn{2}{|l|}{ Highest educational qualification } \\
\hline Masters or higher & $331(25.5)$ \\
\hline Bachelor & $373(28.8)$ \\
\hline Diploma & $187(14.4)$ \\
\hline Certificate & $252(19.4)$ \\
\hline Other & $39(3.0)$ \\
\hline Missing & $115(8.9)$ \\
\hline \multicolumn{2}{|l|}{ Household structure } \\
\hline Person living alone & $16(1.2)$ \\
\hline Couple only & $43(3.3)$ \\
\hline Couple with child(ren) & $973(75.0)$ \\
\hline Single parent with child(ren) & $207(16.0)$ \\
\hline Others & $49(3.8)$ \\
\hline Missing & $9(0.7)$ \\
\hline \multicolumn{2}{|l|}{ Country of birth } \\
\hline Australia & $1025(79.0)$ \\
\hline Other & $254(19.6)$ \\
\hline Missing & $18(1.4)$ \\
\hline
\end{tabular}

support autistic people (measured on a five-point scale ranging from 1 (strongly agree) to 5 (strongly disagree), with an additional 'not sure' option); as well as perceptions that people are aware of 10 key characteristics/ impacts of autism (measured on a four-point scale (most/ some/few/none) with a fifth 'not sure' option).

- What they would like the community to understand: the three things about autism they would like others to be aware of (open-ended).

The questionnaire commenced with questions about the respondent's or their family member's diagnosis and whether they were responding in the context of their personal experience as an autistic person or the family member/carer of an autistic person. Respondent demographics were also collected; including age, gender, and educational attainment.

\section{Analysis}

Descriptive statistics have been used to summarise survey data. The summary statistics are reported as frequencies and percentages for all categorical variables. To examine the relationship between two variables measured at the nominal or ordinal level of measurement, bivariate tables (or contingency tables) were prepared. To test the association between variables (such as differences by age group or gender), generalised linear model (GLM) was applied to binary response variable, and chi-square tests were performed for all other categorical data. The results for the GLM are expressed as odds ratios (OR) with $95 \%$ confidence intervals (95\% CI) along with p-value. All analyses were performed in statistical software R (R Core Team 2019) version 3.5.3.

On completion of the data collection, members of the autistic community were presented with the statistical results and given the opportunity to comment on the findings. Three autistic autism researchers who were not involved in the study were invited to review the interpretation results presented in the manuscript. The results are presented below for all 1297 included respondents. As the number of autistic people responding on behalf of themselves was small $(\mathrm{n}=57 ; 4 \%)$, statistical comparisons between this group and the rest of the sample were not undertaken; however, given the importance of hearing autistic voices, key findings from this group are presented descriptively at the end of each section of the results.

\section{Results}

\section{Diagnosis}

The majority (92.8\%) of respondents reported that they or the family member/person they care for has received a formal diagnosis of autism; $5.8 \%$ had not and $1.3 \%$ were unsure. We found no differences between these groups for the results in both Tables 5 and 6. Respondents who were reporting on a child under the age of 18 , or a person (or themselves) aged 18-24 overwhelmingly reported that the person has a formal diagnosis $(98.0 \%$ and $97.0 \%$ respectively); compared to $72.6 \%$ of those aged $25-44$ and $29.5 \%$ of those aged 45 and over $\left(\chi^{2}=150.3, p<0.001\right)$.

\section{Supports and Services}

The majority of respondents (70\%) reported that they/their family member receives external support (e.g. therapy, counselling, disability support person) for their daily living. Of 
Table 5 Descriptive statistics for study two participants' perception of community attitudes to autism

\begin{tabular}{|c|c|c|c|c|c|c|}
\hline Statement: Most people I come across... & $\begin{array}{l}\text { Strongly } \\
\text { agree \% }\end{array}$ & Agree $\%$ & $\begin{array}{l}\text { Neither agree or } \\
\text { disagree } \%\end{array}$ & Disagree $\%$ & $\begin{array}{l}\text { Strongly } \\
\text { disagree \% }\end{array}$ & Unsure \% \\
\hline Have heard of autism & 27.4 & 59.9 & 5.8 & 5.2 & 1.2 & 0.5 \\
\hline Know how autism might affect someone's behaviour & 1.5 & 14.3 & 12.9 & 42.3 & 27.6 & 1.4 \\
\hline Know how to support autistic people & 0.5 & 3.2 & 9.9 & 44.1 & 41.2 & 1.1 \\
\hline
\end{tabular}

Table 6 Descriptive statistics for study two participants' perceptions of community awareness of how autism can affect people

\begin{tabular}{lcllll}
\hline Statement & Most $\%$ & Some $\%$ & Few $\%$ & None $\%$ & Unsure $\%$ \\
\hline Difficulties in social situations & 18.0 & 34.6 & 39.3 & 7.1 & 1.0 \\
Meltdowns & 14.0 & 29.8 & 44.8 & 9.9 & 1.5 \\
Stimming (e.g. waving hands) & 10.5 & 28.5 & 46.5 & 12.2 & 2.3 \\
Anxiety about unexpected changes & 5.8 & 23.5 & 56.1 & 13.1 & 1.5 \\
Making noise & 5.1 & 25.3 & 52.4 & 14.8 & 2.4 \\
Literal interpretation of language & 4.4 & 17.3 & 59.1 & 17.0 & 2.2 \\
Sensory sensitivity & 4.3 & 20.7 & 57.7 & 16.2 & 1.1 \\
Using language that seems odd & 4.4 & 20.0 & 58.4 & 15.0 & 2.2 \\
Wandering/absconding & 4.1 & 23.7 & 52.8 & 15.6 & 3.8 \\
Needing extra time & 3.6 & 14.9 & 62.1 & 18.0 & 1.4 \\
\hline
\end{tabular}

those 361 who do not currently receive services, $59.8 \%$ $(n=216)$ reported that they need external support and $16.6 \%$ $(n=60)$ were unsure.

There was a linear association between the age of autistic children and being in receipt of support $\left(\chi^{2}=90.02\right.$, $\mathrm{p}<0.001)$. The majority of children aged $0-5$ years were currently receiving support (89.4\%); compared to $72.8 \%$ of those aged $6-12$ years and $58.6 \%$ aged $13-17$ years. This continued for adults, with $69.3 \%$ of those aged $18-24$ receiving support, compared to $50.6 \%$ of those aged $25-44$ and $27.3 \%$ of those aged 45 and over. ${ }^{3}$

Of those currently receiving services, $42.8 \%(n=389)$ reported that the level of support is inadequate and a further $9.4 \%(n=85)$ were unsure. There was an association between the age of the autistic person and the perception that support was inadequate to meet the individual's needs. Approximately one-quarter $(27.1 \%)$ of those responding on behalf of someone aged $0-5$ years reported that the support was inadequate, increasing to $45.1 \%$ for those aged 6-12 years, $60.0 \%$ of those aged $13-17$ years, and $55.7 \%$ of those aged $18-34$ years. ${ }^{4}$

Just under half $(49 \%, \mathrm{n}=28)$ of the 57 autistic respondents who responded in relation to their own experiences reported that they receive any external support. Of the 28 who were not, nine reported that they need support, nine that they do not, and 10 were unsure. Of those who do receive support, $48 \%(n=13)$ believe the level of support they receive is inadequate and $52 \%(\mathrm{n}=14)$ that it is adequate or about right.

\section{Perceived Community Awareness}

The majority of respondents (87.3\%) agreed that most people in the community have heard of autism; but few perceive that most people know how autism might affect someone's behaviour $(15.3 \%)$ and even fewer $(3.7 \%)$ that they know how to support autistic people (see Table 5). This was consistent for the 57 respondents who identified as autistic and responded in relation to their own experiences $(86 \%, 14 \%$, and $2 \%$ respectively).

The only characteristics of how autism may affect people that more than $10 \%$ of respondents felt 'most people' would be aware of were: difficulties in social situations (18\%), meltdowns (14\%), and stimming (10\%). More than two-thirds perceived that few or no people in the community would be aware that autistic people may need extra time $(80.1 \%)$, have literal interpretation of language (76.3\%), have sensory sensitivity (73.9\%), use language that seems odd (73.5\%), experience anxiety about unexpected changes $(69.3 \%)$, wander or abscond (68.6\%), and make noise (67.1\%) (see Table 6).

\section{What They Would like the Community to Understand}

The most commonly selected things about autism that they would like other people to be aware of were difficulties in social situations (61.8\%), anxiety about unexpected changes (58.8\%), and needing extra time (58.6\%). Other common responses were: sensory sensitivities $(37.2 \%)$, meltdowns (29.1\%), literal interpretation of language (20.2\%), using 
language that seems odd (11.6\%), making noise (10.7\%), and stimming (e.g. waving hands) (8.8\%).

Of the 57 autistic respondents who responded in relation to their own experiences, the top things they would most like other people to be aware of were: anxiety about unexpected changes $(70 \%)$, difficulties in social situations $(63 \%)$, needing extra time (58\%), and sensory sensitivity (53\%).

\section{Discussion}

\section{Prevalence, Causation and 'Cure'}

It is clear that the majority of Australians have heard of autism, but that there are significant gaps in their knowledge and understanding of the condition and its impacts. More than half of the Study One respondents were aware that the number of (diagnosed) autistic people in Australia is increasing, although only slightly more than one-third were aware that this is the case for females. This suggests a need to increase awareness of the prevalence of autism among girls and the differences between males and females in presentation of autism.

The longevity of myths around autism, and the need for greater education, was evident in the area of causation, with significant proportions of Study One respondents unconvinced or unsure of the facts. For example, more than one in five believed that, or were unsure whether, vaccines cause autism; and more than a third did not believe that, or were unsure whether, autism can be inherited or genetic. It was concerning to note that those with close relatives who are autistic were more likely than the general population or autistic people themselves to incorrectly believe that autism is caused by vaccines like MMR. Future research could explore the reasons for this difference; for example, it may be due to the psychological need experienced by some for an explanation for their relative's autism (Mercer, Creighton, Holden, and Lewis 2006); or the strong influence of anecdotal evidence, such as emotive media coverage (Nagaraj 2006), which would have more salience for family members of autistic people.

Just under half of the non-autistic sample thought autism can be 'cured' or were unsure whether it can be cured. More than one-fifth were unsure whether people 'grow out' of autism or thought they did. These misperceptions, which were particularly prevalent among male respondents, are potentially harmful to autistic people and their families. The belief that children can be 'cured' or can 'grow out' of autism can lead parents to embark on expensive and potentially harmful treatments (Boseley 2018), make parents feel that their child's autism is a reflection of their failure to provide the right support (Courcy and Des Rivières 2017), and prevent parents from recognising and accepting their child's strengths. For the autistic person, it can also lead to a lifetime of perceiving themself to be a failed neurotypical person (Cage et al. 2018) rather than a successful autistic person (Ken and Solvegi 2016). A positive autistic social identity has been found to buffer against negative psychological outcomes for autistic adults, such as anxiety and depressive symptoms (Cooper et al. 2017).

The societal and economic impact of this misperception is evident in the findings in relation to provision of support. The linear decrease across age groups in receipt of external support, and adequate levels of external support, demonstrates the failure of governments to recognise and support the needs of autistic adults (and older children transitioning to adulthood). This is consistent with UK research which found almost half of autistic adults expressing a desire to receive support were not receiving any (Camm-Crosbie et al. 2019). In the Study Two sample, $90 \%$ of autistic children aged 0-5 years were receiving support; but only $59 \%$ aged 13-17 years were receiving external support, with $60 \%$ of those receiving less support than they needed. This failure to provide necessary support services to students in secondary school is reflected in the low levels of post-secondary education and employment attainment amongst autistic people. In Australia, of those autistic people who complete secondary school, only $32.5 \%$ receive a post-school qualification, compared with $66.2 \%$ of those with any form of disability and 70.1\% of those without a disability (ABS 2018). In 2015 the unemployment rate for people with an autism diagnosis was $31.6 \%$; more than three times the rate for people with any disability (10\%) and almost six times the rate of people without disability (5.3\%) (ABS 2015).

\section{Outcomes and Impacts}

In Study One, significant knowledge gaps were also identified in the areas of outcomes and impacts, particularly among the non-autistic sample. The majority reported being aware that autism affects everyone differently, and that autistic people may be sensitive to light and noise, have difficulty making friends, and struggle to gain employment. However, more than half believed or were unsure whether schools can refuse to enrol an autistic student. In Australia, schools must "ensure that students with disabilities... are accommodated to participate in education on the same basis as their peers" (Victoria State Government Education and Training 2019). However, the reality for many children is that the failure of the education system to adequately support their needs and provide the resources needed by school staff, results in social isolation and school exclusion (Brede et al. 2017).

Almost one in five believed that autistic people are often violent and a similar proportion were unsure whether this is the case. This misperception, which was more prevalent among females and respondents with lower education, is 
likely due at least in part to sensationalist media coverage of autism and over-reporting of (real or suggested) autism diagnoses among high-profile criminals (Brewer et al. 2017; Jones and Harwood 2009; Kang 2013). Several comprehensive studies have shown that, after accounting for co-occurring conditions, autistic people are equally or less likely to commit violent crimes (Ghazziuddin 2013; Heeramun et al. 2017; King and Murphy 2014); and that autistic people are more likely to be victims of crime/assault than to be perpetrators (Weiss and Fardella 2018).

Encouragingly, younger respondents in Study One's general population sample were more likely to be aware that autism affects everyone differently and less likely to believe that people with autism are often violent or should go to a specialist school; suggesting that increasing discussion of autism in public forums and increasing contact with autistic peers in mainstream schooling may be starting to break down some of the myths and misperceptions surrounding autism. While respondents in Study Two (who are autistic and/or parents or carers of autistic people) agree that most people in the community have heard of autism, the majority perceive that the community's awareness of autism does not extend to understanding how autism might affect someone's behaviour and how to support autistic people.

Those with lived experience report reasonable levels of community awareness of the more visible and stereotypical characteristics of autism, such as difficulties in social situations, meltdowns, and stimming. However, they experience that the majority of people in the community are not aware that autistic people may need extra time, have literal interpretations of language, have sensory sensitivities, use language that seems odd, experience anxiety about unexpected changes, wander or abscond, and make noise. It is perhaps not surprising that visible, externalised aspects are more accessible to non-autistic people who have limited exposure to autistic people in their daily lives. For many of these people their 'understanding' will have come from portrayals in the entertainment media, which typically focus on more visible and stereotypical characteristics of autism (Conn and Bhugra 2012; Garner et al. 2015).

These gaps between community reports of their awareness of the impacts of autism and the lived experience of autistic people suggest that this 'awareness' may be superficial and that there is a need for a deeper and more nuanced understanding. For example, $84 \%$ of the Study One's nonautistic sample reported being aware that autistic people may be sensitive to light and noise, but almost three-quarters of the Study Two respondents reported that no or few people in the community are aware of how sensory sensitivities can affect autistic people. Sensory processing difficulties - which can involve any of the senses - are a reality for the majority of autistic adults (Crane et al. 2009), as they are for autistic children. These sensory sensitivities are a significant contributor to increased anxiety levels (South and Rodgers 2017; Wigham et al. 2015), and therefore raising awareness and encouraging environmental modifications can facilitate inclusion for autistic children and adults.

\section{Limitations}

The non-autistic sample in Study One was largely representative of the Australian population and the sample size ( $n=2424$ total; 2081 general population) sufficient to enable confidence in the data. However, the sample was more highly educated than the Australian population which may mean, for example, that knowledge gaps are underestimated. It is also important to note that some of the responses are likely to be influenced by social desirability bias, a common issue with any self-report data.

The Study Two sample size was sufficiently large to enable confidence in the data. However, the low response rate $(9.4 \%)$ and the fact that the sample was sourced from subscribers to the Amaze e-Spectrum newsletter, means that generalisation to the underlying population of autistic people and their families/carers (and particularly those living outside Victoria) should be undertaken with caution. It should also be noted that the sample was predominantly female and predominantly family members/carers caring for autistic children. The likelihood that this sample is more knowledgeable about autism and more able to seek out information and resources than the underlying population means that the needs, concerns, and negative experiences of autistic people and their carers may be underestimated.

The small number of autistic respondents prohibited meaningful analyses of statistically significant differences in views and experiences between autistic people and those caring for people with autism; this was exacerbated by the allocation of some autistic people who were also carers to report on the experiences of the person they care for rather than their own. The use of unique measures in the surveys was both a strength and a limitation; a strength in that the instruments were developed in consultation with autistic people and their carers to ensure both respectful language and the inclusion of key issues of importance, but a limitation in that these were not validated measures that have been used with other samples.

The findings reported in this study used primarily Likertstyle response options. Future research should test the most effective method for capturing knowledge, such as Likertstyle responses versus autism vignettes versus true/false questions. While our questionnaire was tailored to an Australian context, it may also be useful to test the measures in another context to understand its cross-cultural utility (Harrison et al. 2017). Further research could also include the formal autism diagnostic categories in the data collection, to see if there is a difference among the autistic community 
as to what their priorities are for community awareness and attitudes based on level of need/diagnosis.

\section{Conclusion}

These were the first Australian studies to explore in depth the autism-related attitudes and knowledge of the general population and establish a clear agenda for reducing discrimination and increasing acceptance. The studies also add to the global body of knowledge in relation to community attitudes. The findings in relation to myths and misunderstandings are consistent with research in other countries; particularly in relation to the perception of autistic people as unempathetic, socially disengaged, and potentially violent (John et al. 2018).

The disconnect between community perceptions of their understanding of the impacts of autism and the experiences of autistic people and their families demonstrates a need to better educate the general public about the needs of autistic people and the ways in which communities, organisations, and governments can support greater acceptance and inclusion for autistic children and adults. As noted by Cage et al. (2019), if we are to reduce autism stigma and break down stereotypes "autistic adults themselves must be a key source of information for improving non-autistic individuals' attitudes". Thus, there is a need for more research which integrates the perspectives of both autistic people and the broader community; and for this research to inform the development of communication and education interventions, with rather than about autistic people.

Funding This study was funded by Amaze.

\section{References}

Australian Bureau of Statistics (ABS). (2015). Autism in Australia. https://www.abs.gov.au/ausstats/abs@.nsf/Lookup/4430.0Main $\% 20$ Features 752015 .

ABS. (2016b). Education and Work, Australia, May 2016. https://www. abs.gov.au/AUSSTATS/abs@.nsf/DetailsPage/6227.0May\%20201 6? OpenDocument.

ABS. (2016a). Australian Demographic Statistics, Sep 2016. https://www.abs.gov.au/AUSSTATS/abs@.nsf/DetailsPag e/3101.0Sep\%202016?OpenDocument.

ABS. (2018). Survey of Disabiltiy. Customised Data Report: Ageing and Carers.

AIHW. (2017). Autism in Australia. Accessed:https://www.aihw.gov. $\mathrm{au} / \mathrm{reports} /$ disability/autism-in-australia/contents/autism.

Bargiela, S., Steward, R., \& Mandy, W. (2016). The experiences of late-diagnosed women with autism spectrum conditions: An investigation of the female autism phenotype. Journal of Autism and Developmental Disorders, 46(10), 3281-3294. https://doi. org/10.1007/s10803-016-2872-8.

Baron-Cohen, S. (2017). Editorial Perspective: Neurodiversity - a revolutionary concept for autism and psychiatry. The Journal of Child Psychology and Psychiatry, 58, 744-747. https://doi.org/10.1111/ jcpp. 12703.

Bennett, M., Webster, A. A., Goodall, E., \& Rowland, S. (2018). Exploring the identity of autistic individuals: Reconstructing the autism epidemic myth in Life on the Autism Spectrum: Translating Myths and Misconceptions into Positive Futures. Springer Nature

Bent, C. A., Barbaro, J., \& Dissanayake, C. (2020). Parents' experiences of the service pathway to an autism diagnosis for their child: What predicts an early diagnosis in Australia? Research in Developmental Disabilities. https://doi.org/10.1016/j.ridd.2020.103689.

Boseley, S. (2018). More than 120 homeopaths trying to 'cure' autism in UK. The Guardian https://www.theguardian.com/society/2018/ apr/27/more-than-120-homeopaths-trying-to-cure-autism-in-uk.

Brede, J., Remington, A., Kenny, L., Warren, K., \& Pellicano, E. (2017). Excluded from school: Autistic students' experiences of school exclusion and subsequent re-integration into school. Autism \& Developmental Language Impairments, 2, 1-20. https://doi. org/10.1177/2396941517737511.

Brewer, N., Zoanetti, J., \& Young, R. L. (2017). The influence of media suggestions about links between criminality and autism spectrum disorder. Autism, 21, 117-121. https://doi.org/10.1177/13623 61316632097.

Cage, E., Di Monaco, J., \& Newell, V. (2019). Understanding, attitudes and dehumanisation towards autistic people. Autism, 23, 1373-1383. https://doi.org/10.1177/1362361318811290.

Cage, E., Monaco, J., \& Newell, V. (2018). Experiences of Autism Acceptance and Mental Health in Autistic Adults. Journal of Autism and Developmental Disorders, 48, 473-484. https://doi. org/10.1007/s 10803-017-3342-7.

Camm-Crosbie, L., Bradley, L., Shaw, R., Baron-Cohen, S., \& Cassidy, S. (2019). 'People like me don't get support': Autistic adults' experiences of support and treatment for mental health difficulties, self-injury and suicidality. Autism, 23(6), 1431-1441. https://doi. org/10.1177/1362361318816053.

Conn, R., \& Bhugra, D. (2012). The portrayal of autism in Hollywood films. International Journal of Culture and Mental Health, 5(1), 54-62. https://doi.org/10.1080/17542863.2011.553369.

Cooper, K., Smith, L. G., \& Russell, A. (2017). Social identity, selfesteem, and mental health in autism. European Journal of Social Psychology, 47(7), 844-854.

Courcy, I., \& Des Rivières, C. (2017). "From cause to cure": A qualitative study on contemporary forms of mother blaming experienced by mothers of young children with autism spectrum disorder. Journal of Family Social Work, 20(3), 233-250. https://doi. org/10.1080/10522158.2017.1292184.

Crane, L., Goddard, L., \& Pring, L. (2009). Sensory processing in adults with autism spectrum disorders. The International Journal of Research and Practice, 13, 215-228. https://doi. org/10.1177/1362361309103794.

Cummins, C., Pellicano, E., \& Crane, L. (2020). Autistic adults' views of their communication skills and needs. International Journal of Language \& Communication Disorders. https://doi. org/10.1111/1460-6984.12552.

Davidson, M. (2017). Vaccination as a cause of autism-myths and controversies. Dialogues in clinical neuroscience, 19(4), 403-407. https://doi.org/10.24087/IAM.2017.1.11.35.

den Houting, J. (2018). Neurodiversity: An insider's perspective. Autism, 23(2), 271-273. https://doi.org/10.1177/1362361318820762.

Dillenburger, K., Jordan, J. A., McKerr, L., Devine, P., \& Keenan, M. (2013). Awareness and knowledge of autism and autism interventions: A general population survey. Research in Autism 
Spectrum Disorders, 7, 1558-1567. https://doi.org/10.1016/j. rasd.2013.09.004.

Dosch, R. (2019). Resisting Normal: Questioning Media Depictions of Autistic Youth and Their Families. Scandinavian Journal of Disability Research, 21(1), 150-157. https://doi.org/10.16993/sjdr.56.

Durand-Zaleski, I., Scott, J., Rouillon, F., \& Leboyer, M. (2012). A first national survey of knowledge, attitudes and behaviours towards schizophrenia, bipolar disorders and autism in France. BMC Psychiatry, 12, 128. https://doi.org/10.1186/1471-244X-12-128.

Fletcher-Watson, S., \& Bird, G. (2019). Autism and empathy: What are the real links? Autism. https://doi.org/10.1177/1362361319883506.

Garg, P., Lillystone, D., Dossetor, D., Eastwood, J., \& Liaw, S. T. (2016). A pilot study for understanding the perceptions of Australian general practitioners regarding psychopharmacology for children with autism spectrum disorders. Journal of Primary Care and Community Health, 7(4), 258-264. https://doi.org/10.1177/2150131916 644030.

Garner, A., Jones, S., \& Harwood, V. (2015). Authentic representations or stereotyped "outliers": using the CARS2 to assess film portrayals of Autism Spectrum Disorders. International Journal of Culture and Mental Health, 8, 414-425. https://doi.org/10.1080/17542 863.2015.1041993.

Geoghegan, S., Callaghan, K. P., \& Offit, P. A. (2020). Vaccine Safety: Myths andMisinformation. Frontiers in Microbiology. https://doi. org/10.3389/fmicb.2020.00372.

Geoghegan, S., O'Callaghan, K. P., \& Offit, P. A. (2020). Vaccine Safety: Myths and Misinformation. Frontiers in Microbiology. https://doi. org/10.3389/fmicb.2020.00372.

Ghazziuddin, M. (2013). Violent behavior in autism spectrum disorder: is it a fact, or fiction? Current Psychiatry, 12, 23.

Hadjikhani, N. (2014). Scientifically deconstructing some of the myths regarding autism. Schweizer Archiv fur Neurologie und Psychiatrie, 165, 272-276. https://doi.org/10.4414/sanp.2014.00297.

Harrison, A. J., Slane, M. M., Hoang, L., \& Campbell, J. M. (2017). An international review of autism knowledge assessment measures. Autism, 21(3), 262-275. https://doi.org/10.1177/136236131663878 6.

Heeramun, R., Magnusson, C., Gumpert, C. H., Granath, S., Lundberg, M., Dalman, C., \& Rai, D. (2017). Autism and Convictions for Violent Crimes: Population-Based Cohort Study in Sweden. Journal of the American Academy of Child \& Adolescent Psychiatry, 56, 491497.e492. https://doi.org/10.1016/j.jaac.2017.03.011.

Jacoby, E. C., Walton, K., \& Guada, J. (2019). Community Perspectives on Adults With Autism Spectrum Disorder. Occupational Therapy in Mental Health, 35(1), 72-91. https://doi.org/10.1080/01642 12X.2018.1507774.

Jensen, C. M., Martens, C. S., Nikolajsen, N. D., Skytt Gregersen, T., Heckmann Marx, N., Goldberg Frederiksen, M., \& Hansen, M. S. (2016). What do the general population know, believe and feel about individuals with autism and schizophrenia: Results from a comparative survey in Denmark. Autism, 20, 496-508. https://doi. org/10.1177/1362361315593068.

John, R. P. S., Knott, F. J., \& Harvey, K. N. (2018). Myths about autism: An exploratory study using focus groups. Autism, 22, 845-854. https ://doi.org/10.1177/1362361317714990.

Jones, S. (2019). We need to stop perpetuating the myth that children grow out of autism https://theconversation.com/we-need-to-stopperpetuating-the-myth-that-children-grow-out-of-autism-119540.

Jones, S. C., \& Harwood, V. (2009). Representations of autism in Australian print media. Disability \& Society, 24, 5-18. https://doi. org/10.1080/09687590802535345.

Kang, S. (2013). Coverage of autism spectrum disorder in the US television news: an analysis of framing. Disability \& Society, 28(2), 245-259. https://doi.org/10.1080/09687599.2012.705056.
Ken, G., \& Solvegi, S. (2016). Autistic Identity Development and Postsecondary Education. Disability Studies Quarterly. https://doi. org/10.18061/dsq.v36i3.5053.

King, C., \& Murphy, G. (2014). A Systematic Review of People with Autism Spectrum Disorder and the Criminal Justice System. Journal of Autism and Developmental Disorders, 44, 2717-2733. https://doi. org/10.1007/s10803-014-2046-5.

May, T., Sciberras, E., Brignell, A., \& Williams, K. (2017). Autism spectrum disorder: Updated prevalence and comparison of two birth cohorts in a nationally representative Australian sample. BMJ Open, 7(5), 1-9. https://doi.org/10.1136/bmjopen-2016-015549.

Mazurek, M. O. (2014). Loneliness, friendship, and well-being in adults with autism spectrum disorders. Autism, 18, 223-232. https://doi. org/10.1177/1362361312474121.

McClain, M. B., Harris, B., Haverkamp, C. R., Golson, M. E., \& Schwartz, S. E. (2020). The ASKSP Revised (ASKP-R) as a measure of ASD knowledge for professional populations. Journal of Autism and Developmental Disorders, 50, 998-1006. https://doi. org/10.1007/s10803-019-04321-5.

Mercer, L., Creighton, S., Holden, J., \& Lewis, M. (2006). Parental Perspectives on the Causes of an Autism Spectrum Disorder in their Children. J Genet Counsel, 15(1), 41-50. https://doi.org/10.1007/ s10897-005-9002-7.

Nagaraj, A. (2006). Does qualitative synthesis of anecdotal evidence with that from scientific research help in understanding public health issues: A review of low MMR uptake. European Journal of Public Health, 16(1), 85-88. https://doi.org/10.1093/eurpub/cki058.

Russell, G., Collishaw, S., Golding, J., Kelly, S. E., \& Ford, T. (2015). Changes in diagnosis rates and behavioural traits of autism spectrum disorder over time. BJPsych open, 1, 110. https://doi.org/10.1192/ bjpo.bp.115.000976.

Segall, M. J. (2008). Inclusion of students with autism spectrum disorder: educator experience, knowledge, and attitudes. Master's Thesis, University of Georgia, Athens, GA.

Solomon, C. (2020). Autism and Employment: Implications for Employers and Adults with ASD. Journal of autism and developmental disorders. https://doi.org/10.1007/s10803-020-04537-w.

South, M., \& Rodgers, J. (2017). Sensory, Emotional and Cognitive Contributions to Anxiety in Autism Spectrum Disorders. Frontiers in Human Neuroscience. https://doi.org/10.3389/fnhum.2017.00020.

Victoria State Government Education and Training. (2019). School Policy: Students with a disability https://www.education.vic.gov. au/school/principals/spag/participation/Pages/studentswithdisabili ty.aspx.

Weiss, J. A., \& Fardella, M. A. (2018). Victimization and Perpetration Experiences of Adults With Autism. Frontiers in Psychiatry. https ://doi.org/10.3389/fpsyt.2018.00203.

Wigham, S., Rodgers, J., South, M., McConachie, H., \& Freeston, M. (2015). The Interplay Between Sensory Processing Abnormalities, Intolerance of Uncertainty, Anxiety and Restricted and Repetitive Behaviours in Autism Spectrum Disorder. Journal of Autism Developmental Disorders, 45, 943-952. https://doi.org/10.1007/s1080 3-014-2248-x.

Zolyomi, A., \& Tennis, J. T. (2017). Autism Prism: A Domain Analysis Examining Neurodiversity. NASKO, 6, 139-172. https://doi. org/10.7152/nasko.v6i1.15237.

Publisher's Note Springer Nature remains neutral with regard to jurisdictional claims in published maps and institutional affiliations. 